\title{
Lexical Cohesion Grammatical Markers in Scientific Papers
}

\author{
Pidia Ananda Sari, Ermanto, Agustina \\ Faculty of Languages and Arts, UNP \\ pidiaanandasari@gmail.com,
}

\begin{abstract}
The purpose of this study was to describe the shape of cohesion lexical and grammatical markers appropriate and inappropriate in a scientific paper. The research is a qualitative study using descriptive analysis method. The data source of this research is the thesis students of Indonesian Language and Literature Education STKIP Lubuk YDB Alung devoted to the background of the problem as much as 20 theses in 2017. The data in this study are sentences that contain lexical and grammatical markers cohesion in scientific papers student of Indonesian Language and Literature Education STKIP Lubuk YDB Alung which are words or phrases that are in between the words or phrases, intrakalimat, antarkalimat or antarparagraf. The results showed that the use of lexical cohesion markers there are two forms of correct and inappropriate form of lexical cohesion pemarkah. Markers of appropriate lexical cohesion include synonymy, repetition, antonymy, hyponimi, equivalence and collocation, whereas inappropriate lexical cohesion marker forms include repetitions and synonyms. The use of grammatical cohesion markers there are two forms of precise and inappropriate grammatical cohesion shapes. Appropriate grammatical cohesion markers include conjunctions, references, ellipsis and substitutions, whereas inappropriate lexical cohesion marker forms include ellipsis, conjunctions, references and substitutions. The most dominant form of cohesion marker used in the student's thesis STKIP YDB Lubuk Alung is a form of conjunction marker that is coordinative conjunction.
\end{abstract}

Keywords-Markers; cohesion; lexical; grammatical; scientific papers

\section{INTRODUCTION}

Discourse as the basis for understanding the text is needed by the community of language in conveying information. The text is composed by elements related to each other so as to create a unified whole that forms of discourse. To be able to assess the discourse well, the necessary understanding of such fundamental concepts about the intricacies of discourse and knowledge called discourse analysis (Baryadi, 2002).In addition, the discourse is the most complete and highest unity of language, or the largest of the sentence or clause with the cohesion and coherence of high and sustainable and can be delivered orally and in writing. In oral discourse, penyapa is a speaker, while pesapa is listener. However, in written discourse, penyapa is the author, while pesapa are readers (Nurfitriani, Bahry, R. Azwardi, 2016, p. 71), Thus, between writer and reader communication occurs indirectly. Therefore, ideas, concepts, thoughts and ideas of the writer should be well-organized and intact in order to dipahamioleh reader clearly.

Research on discourse analysis have been carried out by previous investigators. Researchers who studied the discourse analysis of which is Anjani (2013), Mandia (2015), Even (2015), Aghdam and Hadidi (2015), and Sarasati (2017). Based on these studies, it is known that previous research simply mendeskripisikan use of these forms of cohesion markers. That is, researchers only saw the use of forms of cohesion markers contained in the discourse and the lack of assessment of the uses of lexical and grammatical markers cohesion inscientific papers.It is one of the factors behind the author to renew research on discourse analysis of aspects of cohesion in scientific papers.

Etymologically imiah paper consists of the phrase 'paper' and the word 'science' (Gani, 2013). The paper is the result of a writing activity. The results of this paper can be in the form of lecture notes, diaries, papers, short story, essay, poetry, theses, novels, comics, and others, while science is anything that is scientific. Science is knowledge that has been verified. Ideally, the scientific work is the best work of the results of the writing skills that have been prepared by the students. This is because scientific work is the work of a scientist (in the form of the development) who want to develop science, technology and art gained through literature, a collection of experiences, research, and prior knowledge of the other person (Khori, 2013, p. 689). A variety of scientific papers written discourse that demands the application of the rules of language and compliance aspects of the language as a condition of a good scientific article and can be understood by the reader. Therefore, a scientific paper should have aspects that are integrated and fused that determines the integrity of the discourse. Aspects question of which is the aspect of cohesion. Cohesion aspects with regard to the relationship between the shape of the parts in a discourse (Anjani, 2013, p. 288). Aspects question of which is the aspect of cohesion. Cohesion aspects with regard to the relationship between the shape of the parts in a discourse (Anjani, 2013, p. 288). Aspects question of which is the aspect of cohesion. Cohesion aspects with regard to the relationship between the shape of the parts in a discourse (Anjani, 2013, p. 288).Links between elements one with the other elements in a discourse can be characterized formally by marker-marker. The markers are in between the words or phrases, intrakalimat, antarkalimat, and antarparagraf. The marker or markers cohesion consists of two parts, namely the cohesion of grammatical and lexical cohesion (Sudaryat, 2011). 
The forms markers grammatical cohesion is that the reference (reference), substitution (substitution), deletion (ellipsis), and the coupling (conjunction), whereas other forms of markers of lexical cohesion is reps (repetitions), synonymy (equivalent word), antonym ( opposite), collocation (collocation) hiponimi (top-down relationship), and the equivalence (equivalence) (Sumarlam et al., 2003). The use of marker-marker lexical and grammatical cohesion, will build a cohesive linkage in a discourse. Thus, the message will be easily understood by the reader.

Based on this insight, it can be said that the cohesion is an important part to get the whole discourse. Careful monitoring to a discourse can only be made in written language, in this research is the discourse of scientific papers, that thesis. In general, a phenomenon that occurs is some students in writing scientific papers only consider its contents only or just to complete the task without regardthe application of the rules of language and compliance aspects of the language as a condition of a scientific paper,

In connection with the issues raised, this study aims to (1) describe the shape of the right marker lexical cohesion in scientific papers, (2) describe the shape of the proper grammatical markers cohesion in scientific papers (3) describe the shape marker improper lexical cohesion in scientific papers, and (4) describe the shape marker improper grammatical cohesion in scientific papers.

\section{METHODS}

The research is a qualitative research with descriptive analysis method. The data in this study are sentences that contain lexical and grammatical markers cohesion in the thesis student of Indonesian Language and Literature Education STKIP Lubuk YDB Alung which are words, phrases or clauses. The data source of this research is the thesis students of Indonesian Language and Literature Education STKIP Lubuk YDB Alung 2017 graduate who majored in the background as much as 20 theses problems. This is due toin this section is the exposure of the process or groove think writers should be codified in a systematic manner. To obtain this required the marker-marker as a liaison, the binder and the referring in the phrase so as to form a coherent unity of meaning that can make it a cohesive discourse.

Sampling in this research is purposive sampling. Purposive sampling is a sampling technique with particular consideration of data sources (Sugiyono, 2009). Instruments in this study is the researchers themselves assisted with laptops, stationery and format of data recording. The method used in collecting data log metodesimak techniques. Mahsun (2007) suggested that meto desimak is the method used in the provision of data by penyimakan use of language by the researcher. This method can be compared with observation or observation that is against the thesis that meet the objectives of this research. Further, the technique is done through the process of determining record data using lexical and grammatical cohesion markers on each essay.

The process of data collection through the stages as follows: (1) that reads and understand the background of student thesis as a whole, (2) indicates the data relating to the form of markers cohesion lexical and grammatical proper and improper in the background of student thesis as a whole ; (3) Perform mutilations data. (4) provide the encoding of the thesis that is used as a data source. Based on data analysis techniques it can be arranged steps of analyzing the data of this study as follows. (1) read data that have been collected as a whole, (2) identify the data that is found (3) classifies data based on subject matter that is related to the forms of markers of lexical cohesion and proper and improper gramatikalyang into the format of the lattice data analysis; (4) conduct discussions, and (5) formulate conclusions and suggestions.

\section{FINDING AND DISCUSSION}

The use of lexical and grammatical cohesion markers in STKIP YDB Lubuk Alung students' thesis are two forms of correct and inappropriate form of pemarkah. The total number of correct lexical and grammatical data form correct and incorrect data was found to be 653 data. The data consists of correct lexical cohesion pemonah as many as 152 data. The most dominant form of pemarkah in correct lexical cohesion is the synonym marker of 53 data. Furthermore, repetition of 49 data, antonymia counted 25 data, hyponimia counted 10 data, equivalence counted 9 data and collocation of 6 data, whereas inappropriate lexical cohesion pemarkah found 18 data. The inaccuracy is in the form of repetition pemarkah as many as 17 data and 1 data on synonymy.

\section{Form of Lexical Cohesion Marker in Scientific Writing}

\subsubsection{Repetition}

The use of repetition markers is found in two forms, namely the use of appropriate and inappropriate reps. The form will be described as follows.

\subsubsection{Use of Proper Reps}

Repetition is the repetition of the same leksem objective of confirming the intention writer or speaker (Sudaryat, 2011). Then, Baryadi (2002) says that repetition is repetition lexical cohesion in the form of a constituent who has been called.Repetition is the repeated use of words, idioms or phrases (Yifan, 2017, p. 74).Repetition is one marker of lexical cohesion which can produce a discourse coherent and easily understood by the reader. In this study found few sentences that use repetition to support the integrity of the discourse. As shown in the following example. 
(1) By producing a human text should change the sound into a sound symbol. The sound emblem assembled into words. Words strung together into sentences. Sentences into paragraphs and assemble into a complete composition.

In the above example there is a sound symbol word at the end of the first sentence. The word is repeated at the beginning of the second sentence. At the end of the second sentence also contained the word and the word was repeated again at the beginning of the third sentence. At the end of the third sentence also includes the word sentence and the word is used to start the fourth sentence. The repetition of the last word of a sentence into the first word at the beginning of the next sentence referred to anadiplosis reps. This means that these words is a form of repetition or recurrence markers aimed at emphasizing to the reader the author's intention is to be conveyed. The linkage between one word with another word that will form a unified form a slick, causing a clear meaning for the reader.

\subsubsection{Use of Inappropriate Repetition}

In analyzing the form of lexical cohesion in scientific papers, the discovery of the inaccurate selection of words in discourse is found. The inappropriateness of the form of cohesion is the form of repetition marker or repetition. It is because of the same word that is not needed to repeat again. Error repetition in a discourse makes the discourse is not coherent and contains a lot of waste. As seen in the following example.

(2) The learning model is in accordance with the criteria and suitability of teaching materials that students learn also help students in overcoming students' difficulties with writing skills.

In the above example there is an imprecise use of lexical cohesion that is repetition marker or repetition. The inaccuracy is due to the student's repeated word in the second sentence and the second sentence. That is, the repetition of the word makes the sentence unambiguous and leads to word delusion. To make the sentence cohesive, it should be used hooks or binders such as the use of referents or appointments that may link the intention of the first sentence with the next sentence.

\subsubsection{Synonymy}

The use of synonymy marker form found two forms namely the use of proper and inappropriate synonyms. The form will be described as follows.

\subsubsection{Proper Use of Synonymy}

Synonymy point is a unit of a word or phrase that looks different but the meaning is the same or similar or different name for the same object (Pateda, 2010). In the present study found a few words or phrases that use the same or similar meaning to support the cohesiveness of a discourse. As shown in the following example.

(3) The many types of text that is in learning, especially pemmbelajaran Indonesian, text producing skills is one kind of text that gives freedom to students to develop an opinion on the event or events that are seen around the neighborhood students.

In the example above shows the synonymy word by word in a sentence. The word is that the events and happenings. The words are a form of marker synonymy. Said events if the terms of the same meaning to the word occurrence. Both these words have a meaning that is equally describe on a matter, case or the like in a case. The use of synonymous words serve to establish the meaning of a relationship between one element with another element in discourse.

\subsubsection{Use of Inappropriate Synonymy}

A synonym may be defined as another name for the same thing or thing or phrase whose meaning is more or less the same as another. Synonyms are a lexical aspect by making use of or choosing words to support the cohesiveness of meaning. However, if the use of words is not appropriate in the discourse, then the discourse becomes incorrect. As seen in the following example.

(4) This section is expressed as identification of phenomena due to the beginning of the explanation of the events described or identified.

The above example shows the inaccuracy of word selection in expressing the synonym of a word. In the data there is the word explained and the word is identified. The word or between the two expresses two words that are synonymous or have the same meaning. However, when viewed in terms of meaning, the two words do not have the same meaning. The basic word of the explanation is light while the basic word of identification is identified. The word light and identification do not have the same meaning. The word light has meaning in viewable circumstances; real; clearly while the meaning of the word identification is a sign of self-knowledge; proof or determination or determination of the identity of a person's objects and so on (KBBI V: online). Therefore, the word explained is not appropriate when it is synonymous with the word identified. 


\subsubsection{Antonymy}

Antonymy show lexical cohesion contained in two or more lingual elements which have a meaning opposite or opposition (Sumarlam, et al,. 2003). Antonym (opposite) is one of the aspects of the way mengoposisikan lexical meaning that one element with another element. As shown in the following example.

(5) The images of taste, look at the first verse of the third row and four with the quotation, "he would feel about the joys and sorrows of our lives". Quote stanzas and lines of poetry over the imagery flavors arising from the power means feeling.

In the above example shows the polar opposition between the words pleasure and sorrow words. The second word is said to be in opposition because there are gradations polar opposition between the two, that is the reality of a very happy, happy, rather happy, a little sad, sad, and very sad. That is, people who do not feel pleasure not necessarily feel sorrow or otherwise people are not sad not necessarily happy. Thus, the second meaning of the word opposition is not absolute, but is a gradation which is contained levels of meaning in these words.

\subsubsection{Hiponimi}

Verhaar (in Pateda, 2001) stated hiponimi is an expression (an ordinary word can also phrases or sentences) whose meaning is considered a part of the meaning of another expression. The word includes several word berhiponim was called hipernim. The use hiponimi as in the following example.

(6) Most of the news can be found through media such as newspapers, radio, television, the Internet and online media. In a news should qualify that is what, who, where, when, why, and how.

Examples of the above sentence 1) there is a media which includes newspapers, radio, television and online media Internet. The word is a form of marker hiponimi because the relationship hipernim and hyponymy and hypernymy. Said the newspaper, radio, television and online media internetmerupakan subordinate and katamedia is superordinatnya. In clause 2) there is a requirement phrases news (superordinate) that includes what, who, where, when, why, and how. (subordinate).

\subsubsection{Collocation}

Collocation is certain associations in using the word choice and word tends to be used side by side (Sumarlam et al., 2003). Berkolokasi words are words that tend to be used in a particular domain or network. Meaning interconnected relationships within those domains can build cohesion kekohesian or discourse. Data berkolokasi discourse can be seen in the following example.

(7) As set out in the curriculum of 2006 contained in the class X SMA second half, with the standards of competence (SK) 12 is "revealing information through writing paragraphs and text to speech" and basic competence (KD) 12.4 is "composing text to speech",

Words such as curriculum, 2006, class, high school, semester 2, standard and basic competencies are the words of the GCC have the same domain that is learning in school. Thus, the unit of the language element is the word berkolokasi that aims to explain the meaning of the interconnected relationship making it easier for the reader to understand the meaning to be conveyed.

\subsubsection{Equivalence}

Equivalence is a word that has the equivalent meaning or meanings adjacent (Sudaryat, 2011). Some words formed as a result of affixation process derived from the same original form called the equivalence. The use of equivalence shown in the following example.

(8) For the novice writer, thought to write it is complicated due to too glued to the rules in writing. Many are stuck to must meet all the rules of writing. Neither the rules of spelling, punctuation or other rules that create confusion when will begin to make a post.

In the example above there said the author, writing, writing and writing. The fourth word is a marker of a form of equivalence. They have the equivalent meaning or meanings are adjacent. The fourth word is an affixation process of writing basic words. Write basic words be caused by their prefixes writer pen-and write basic words. Prefix penfunctioning as a noun formation. So, the author means the person who makes the writing or the writing. Write basic words into writing caused by mem- prefix that serves as the formation of a verb or a verb, so writing a letter or childbirth make a meaningful thought or feeling into dala writing.

Said writing is an amalgamation of konfiks's pen and write basic words. Konfiks pen's function as forming a noun that means writing a process, method or act to write or write. Write basic words into text is caused by the combination of the words with the suffix -an daily basis that functions as a noun-forming action results. Thus, the writing has meaning to write or goods results were written. Thus, the word has four meanings adjacent, comparable or related. The use of words such berekuivalensi discourse discourse generated aims to be coherent. 


\section{Form of Grammatical Cohesion Marker in Scientific Writing}

Utilization of proper grammatical markers cohesion can support kekohesian discourse. Grammatical cohesion is the inter-relationship between the elements with other elements so that these elements can explain other elements or grammatical cohesion keseluruhan.Bentuk marker includes a reference (citation), substitution (substitution), ellipsis (deletion), and conjunctions (coupling).

\subsubsection{Reference (Citation)}

The use of reference marker forms is found in two forms: proper and inappropriate use of references. The form will be described as follows.

\subsubsection{Proper Use of References}

In every language, there are elements of a language not understood by themselves, but instead refers (refer) on other things for the understanding of which is called a reference or citation (Zaimar and Ayu, 2009). In the present study found endofora reference marker that has a reference that are in the text are: 1) that the reference anaphoric, that particular element unit which refers to the element preceding it or refer to the antecedents to the left or refer to elements of the former. The use of anaphoric reference markers like this, that, these and above. 2)Third Persona citation reference or citation that can be expressed with a pronoun or a word that serves to replace a noun or anything dinominakan (Sudaryat, 2011). In this case the citation which refers to the citation persona (person) like he, he, and his. 3)Demonstrative of reference places,refers to the place or location close to the speaker there, and this example, a bit further with it and the speaker, for example, much to the speaker and pointed to the spot for example there explicitly for example Padang. 4) Demonstrative of reference time, ie Nothing refers to the time now, and now is now, for example, the past is yesterday and the first instance, the future for example, tomorrow and the future, and the neutral time eg breakfast and lunch. 5) comparability of reference or comparison and citation kataforis ie one type of grammatical cohesion that is to compare two or more things that have a resemblance or similarity in terms of shape / form, attitude, nature, character, behavior and so on. Words commonly used to compare for example like, like, like, like, equal to, not dissimilar to exactly and exactly the same. Examples of reference or citation seen in the following example.

(9) Learning Indonesian language and literature, has four aspects, namely skills listening, speaking, reading and writing. The four aspects of language skills is very important and can not be separated from each other.

(10) The more often a person to practice writing, of course, the more skilled he was writing and writing quality will certainly be better.

The word in the example 7 is a form of marker that serves as a marker anaforis.Kata appointment has a meaning relationship / relationship as a marker designation refers / refer to the sentence in front of him (left) .Kata that the second sentence refers to four aspects, namely listening skills, speaking, reading and writing. In Example 8 are markers of reference persona that he found in the second sentence. It is a form of marker markers relationship as a third person who showed a person says in the first sentence. This means that both the sentence because of its cohesive affinity refers mutual relationship with one another to support the cohesiveness of a sentence.

\subsubsection{Use of Inappropriate References}

In analyzing the grammatical cohesion of scientific papers, there were errors in the form of reference markers. This is because the referenced reference does not match the referent. The reference type found to be a reference error pronouns persona three. The reference form of the three person pronouns of reference indicated by a syntax error is their form. Syntax errors in a discourse, making the reader does not understand because the form of the marker is not coherent and cohesive, so the message is not delivered properly. This is shown in the following data.

(11) Students are given modeling practices in order to improve learning and help students to solve problems encountered during their learning.

Their form in the example above categorized as a pronoun of the third person (plural) meaning the person in question. Their form refers to the element mentioned earlier, ie the student. That is, the syntactic error lies in the form of a marker that refers to a less precise reference. Thus, the use of their word to refer to students is not appropriate because their words do not point to singular but plural. Supposedly, in that sentence their form is replaced by the form that refers to the (single) student, because the referred is not the students (plural). That way, the form and its reference will look cohesive and precise.

\subsubsection{Substitution (Substitution)}

The use of substitution markers is found in two forms, namely the use of appropriate and inappropriate substitutions. The form will be described as follows.

\subsubsection{Proper Use of Substitution}

Substitution or substitution is one type of grammatical cohesion in the form of reimbursement of certain language unit with another unit of language in the discourse to acquire distinguishing element (Sumarlam et al., 2003) 
Substitusi intended to reduce repetition of the same forms in a discourse. Thus, the substitution of an effort that creates cohesion of a discourse by replacing certain lingual unit (mentioned earlier). By varying the shape will create a monotony which can result in drab readers. As seen in the following data.

(12) Based on our analysis of the performance of poetry student assignment kelasX 2nd TKJ SMK Negeri 1 Sintuh Toboh Tower, researchers set value that can be obtained by students is 58.3. Based on the values obtained, it can be said that the value achieved by the students have not been able to reach KKM set by the school, namely 75.00 .

The word is obtained and achieved in the second sentence in the above example is a variant form of the word obtained in the first sentence. Replacement of the language elements in addition to looking for a variety of forms also to avoid monotony in a sentence.

\subsubsection{Use of Inappropriate Substitution}

Recovery or substitution serves as a means of dynamizing meaning. By making variations of other forms of the previously mentioned elements will make the writing not monotonous which can result in the reader's readiness. However, in writing often the author repeats the same word without searching for another form as a variation of the element in writing so much cause of confusion to the reader. This is shown in the following example.

(13) Writing skills that occur in high school, especially SMA Negeri 1 Padang Sago school result is still below the average completeness of the Indonesian language learning criteria. Bahsawanya, writing skills of students in SMA Negeri 1 Padang Sago tend to have problems or not yet occupied the concept kepenulisannya.

The inaccuracy of the use of substitution as one of the ways to achieve form cohesion in the example above is on the phrase SMA Negeri Padang Sago. The phrase has been mentioned by the author in the first sentence but in the second sentence the author still repeats the whole name of the school without looking for variations of other forms that can replace it. The author should be able to substitute with the word this school or school in the second sentence as a variation of the form of the phrase SMA Negeri Padang Sago.

\subsubsection{Ellipsis (Deletion)}

The use of the ellipsis marker form is found in two forms: the proper and inappropriate use of ellipsis. The form will be described as follows.

2.1.3.1. Proper Use of Ellipses

Sumarlam et al. (2003) describes the deletion (ellipsis) is one type of grammatical cohesion in the form of removal or deletion of certain lingual unit has been mentioned before. Lubis (2011) also says that the ellipsis is the removal of a part of sentence element, Deletion or ellipsis in the discourse theory is generally useful to pursue kepratisan and communication efficiency while maintaining the cohesion of discourse in a way to stimulate the reader to associate and connect the mind to the things that are not explicitly disclosed in the discourse. Although not explicitly stated, but the presence of these elements can be estimated.It is seen in the following data.

(14) Learning Indonesian language and literature, has four aspects, namely $\varnothing$ skills of listening, speaking $\varnothing, \varnothing \varnothing$ reading and writing.

In the above example there is a deletion at the level of the word is the word keterampilanyang eliminated in kalimat.Kalimat above actually are learning Indonesian language and literature, has four aspects, namely skills listening skills, speaking skills, reading skills and writing skills. The two data deletion function is to achieve the practicality, effectiveness of sentences, and to achieve cohesion aspects of discourse.

\subsubsection{Inappropriate Use of Ellipses}

The inappropriateness of using ellipsis is the use of grammatical ellipsis graphing markers that are inconsistent with grammar or programmatic. Such inaccuracies produce ineffective sentences, do not achieve economic value in language usage or sentence efficiency and the unattached aspects of discourse are not present. This appears in the following example.

(15) Third, a background consisting of a place background, a time setting, an atmosphere setting and a social setting.

In the example above there is a language element that should be absorbed in the sentence, but not deleted. In the data there is a repeated background word many times to explain the various backgrounds. Repetition of the word background reduces the economic value or efficiency in the sentence. The background should be in the background, the setting and the social setting being scraped because the background is already represented in the background.

\subsubsection{Conjunction (Coupling)}

The use of the conjunction marker form is found in two forms, namely the inappropriate and inappropriate use of conjunctions. The form will be described as follows.

2.1.3.1. The Right Usage of Conjunctions 
One cohesion grammatical markers that are commonly used in the discourse is a conjunction. Conjunction is a grammatical cohesion is done by connecting the elements with each other elements (Sumarlam et al., 2003). The elements are connected can be words, phrases, clauses or sentences. Some form of conjunctions found in this study are: 1) Conjunction coordinative, ie conjunctions connect two elements of equal or equivalent and serve as additional meaning or additives such as conjunctions and, but, while and as well. 2) Conjunctions subordinating conjunctions are bringing together two such grammatical elements (words, phrases, clauses, or sentences) so that both of them into a single binding. The position of the elements are fastened by subordinating conjunctions are not equal or unequal. Subordinating conjunctions found are subordinating conjunctions tujuanyaitu order, pengakibatan that is so and so, causation that is because, way is to, conditions namely if, and kosesif that though. 3)Conjunction antarkalimat, ie connecting conjunctions between sentences with other sentences. Therefore, these conjunctions always start a new sentence as conjunctions so, then, therefore, other than that, however, the next, thus and vice versa. 4) correlative conjunctions which is a type of connective words or conjunctions connect two sentence elements which are words, frasaatau clause in one sentence. Marker found that ... not only ... but ... An example of the use of conjunctions in scientific papers will be presented as follows.

(16) First, the text strukutr first poem in stanzas rhyme no sampiran, fourth row consists of the contents of the text structure rhyme rhyme because it consists of sampiran and contents, sampiran located in rows 1-2, while the content is located in rows 3-4, apanila well written poem which contained the contents of each line of the poem teersebut students earned a score of 3 .

In the example there are 11 markers form a coordinating conjunctions whilewhich connects between the clauses of the other clauses. Coordinative conjunctions serve as markers relationship conflict between one element to another. That is kalusa sampiran located in rows 1-2 are located in before conjunctionswhilea contradiction of clause contents located in rows 3-4 are located in the following conjunctions while,

(17) Third, the learning model applied by teachers in teaching writing less poetry attract students because teachers only provide theory without being accompanied by exercises AAU learning application to write poetry.

In Example 12 there konjugsi because as a link in a sentence. Conjunction has a meaning as a cause anatar one kalusa with another clause that the clause in the activity producing value nowadays still unsatisfactory and interest clause to produce from the students themselves are still too low.

(18) Writing skills should be a special concern of the whole party assembled in education. However, what happens on the field today, learning to write more described in the form of verbal theory.

In the above example there is a conjunction but who are at the beginning of the second sentence. The Conjunction is one manifestation of conjunctions antarkalimat marker that can connect sentences with other sentences. The marker has a meaning opposition to its previous state. The use of markers but in these sentences make these sentences into sentences which have unity or attachment to each other.

\subsubsection{Inappropriate Use of Conjunctions}

Cooperative conjunctions are conjunctions that connect two or more clauses, the two elements have the same syntactic status and parallel position. The conjunction, therefore, lies not at the beginning of a sentence or not an intercostal conjunction, but an intracalimat conjunction. However, in writing there is often an erroneous use of conjunctions as a liaison in intracalimat and antarkalimat. As seen in the following example.

(19) Productive language activities are activities to convey ideas, thoughts, feelings, messages or information by the author through the means of writing or in writing activities. While understanding is an activity that aims to understand the message contained in a reading through reading activities.

Cooperative conjunction whereas at the beginning of the second sentence becomes imprecise due to the presence of a coordinated conjunction while at the beginning of a sentence. Sentences beginning with a coordinative liaison will make the linguistic form turn into a hanging clause. Such a linguistic form is said to be a hanging clause because the clause in a compound sentence has no parent sentence, but stands alone as a sentence that has no parent sentence. Conjunction while not as an intercostal conjunction, but as an intracalimat or antarklausal conjunction. Thus, the conjunction while the liaison of the two sentences on the above custom becomes wrong or incorrect.

\section{CONCLUSION}

Based on the results of research and discussion of the marker cohesion lexical and grammatical in scientific papers, it can be concluded that the Form marker most predominantly used by students of Education Language and Literature Indonesia STKIP YDB Lubuk Alung in writing scientific papers is the use of shape marker grammatical cohesion is the use of conjunctions as a means of connecting between the words, antarfrasa, antarkaluasa and antarkalimat in discourse. Total percentage of cohesion proper marker was $93.41 \%$ while the percentage of cohesion improper marker was $6.59 \%$. That is, the whole thesis student Indonesian Language and Literature Education STKIP Lubuk YDB Alung have cohesive. Based on these conclusions, the suggestion in this study is that the writer who will 
make a scientific paper need to pay attention to the rules and aspects that can support the cohesiveness of discourse, especially on the use of lexical and grammatical cohesion marker forms in scientific work.

\section{References}

Aghdam, S.H. and Hadidi, Y. (2015). Cohesion and coherence in political newspapers and discussion sections of academic articles. International Journal on Studies in English Language and Literature (IJSELL), 3 (3), 11-22.

Anjani, E.A. (2013). Cohesion and coherence of discourse stand upc omedy France and Indonesia. KAWISTARA, 3 (3), 288-299.

Baryadi, I.P. (2002). Fundamentals of discourse analysis in linguistics. Yogyakarta: Pustaka Gondho Suli.

Gani, E. (2013). The components of scientific papers. Bandung: Pustaka Reka Cipta.

In fact, Z. (2015). Lexical cohesion in academic discourse: exploring Articles applied linguistics research abstracts. Research Journal of English Language and Literature (RJELAL), 3 (4), 291-299.

Khori, M. (2013) The error marker cohesion in non-linguistic student thesis University Pamekasan. NOSI Madura, 1 (6), 689-696.

Lubis, A.H.H. (2011). Pragmatic discourse analysis. Bandung: Space.

Mandia, I.N. (2015). Praskripsi discourse analysis paper polytechnic students majoring in accounting Bali. Social and Humanities Journal, 5 (3), 205-216.

Mahsun, M.S. (2007). Language research methods. Jakarta: PT Raja Grafindo Persada.

Muslich, M. and Maryaeni. (2010). How to write a thesis ?. Jakarta: Earth Literacy.

Nurfitriani, Bahry, R. Azwardi. (2016). Analysis of cohesion and coherence in PBSI student proposal dated 23 December 2014. Unsyiah Student Science Journal, 1 (1), 70-83.

Pateda, M. (2010). Lexical semantics. Jakarta. Rineka Reserved.

Sarasati. (2017). References in class VII student essay. Journal of Education: Theory, Research and Development, 2 (8), 1107-1115.

Sudaryat, Y. (2011). Meaning in discourse. Bandung: Yrama Widya.

Sumarlam, et al. (2003). Theory and practice of discourse analysis. Surakarta: Library Chakra.

Sugiyono. (2009). Quantitative research methods, kuaitatif, and $R \& D$. Bandung: Alfabeta.

Yifan. (2017). Lexical cohesion in English public speeches-taking the Queen's Christmas broadcast as example. International Journal of Arts and Commerce, 6 (3), 70-81

Zaimar, O.K.S. and Ayu B.S. (2009). The study of discourse. Jakarta: The Intercultural Institute. 